\title{
The changing epidemiology of Ebstein's anomaly and its relationship with maternal mental health conditions: a European registry-based study
}

\author{
Breidge Boyle, ${ }^{1}$ Ester Garne, ${ }^{2}$ Maria Loane, ${ }^{1}$ Marie-Claude Addor, ${ }^{3}$ Larraitz Arriola ${ }^{4}$ Clara Cavero-Carbonell, ${ }^{5}$ \\ Miriam Gatt, ${ }^{6}$ Nathalie Lelong, ${ }^{7}$ Catherine Lynch, ${ }^{8}$ Vera Nelen, ${ }^{9}$ Amanda J. Neville, ${ }^{10}$ Mary O'Mahony, ${ }^{11}$ \\ Anna Pierini, ${ }^{12}$ Anke Rissmann, ${ }^{13}$ David Tucker, ${ }^{14}$ Natalia Zymak-Zakutnia, ${ }^{15}$ Helen Dolk ${ }^{1}$ \\ ${ }^{1}$ Centre for Maternal, Fetal and Infant Research, Institute of Nursing and Health Research, Ulster University, Belfast, \\ UK; ${ }^{2}$ Paediatric Department, Hospital Lillebaelt, Kolding, Denmark; ${ }^{3}$ Division of Medical Genetics, CHUV, \\ Lausanne, Switzerland; ${ }^{4}$ Registro Anomalías Congénitas de la CAPV, Public Health Division of Gipuzkoa, Instituto \\ BIO-Donostia, Basque Government, CIBER Epidemiología y Salud Pública-CIBERESP, Bilbao; ${ }^{5}$ Foundation for the \\ Promotion of Health and Biomedical Research in the Valencian Region, Rare Diseases Research Area, Valencia, Spain; \\ ${ }^{6}$ Department of Health Information and Research Guardamangia, Malta; ${ }^{7}$ Paris Registry of Congenital Malformations \\ INSERM U953, Paris, France; ${ }^{8}$ Health Service Executive, Kilkenny, Ireland; ${ }^{9}$ Department of Environment, \\ PIH, Antwerp, Province of Antwerp, Belgium; ${ }^{10}$ Registro IMER - IMER Registry (Emila Romagna Registry of Birth \\ Defects), Azienda Ospedaliero - Universitaria di FerraraCorso Giovecca, Ferrara, Italy; ${ }^{11}$ Health Service Executive, \\ Cork, Ireland; ${ }^{12}$ CNR Institute of Clinical Physiology, Pisa, Italy; ${ }^{13}$ Medical Faculty, Malformation Monitoring Centre, \\ Otto-von-Guericke University, Magdeburg, Saxony-Anhalt, Germany; ${ }^{14}$ Public Health Wales. Swansea, UK; \\ ${ }^{15}$ Khmelnytsky Regional Medical Genetic Centre, Rivne, Ukraine
}

\begin{abstract}
Objectives: The aim of this study was to describe the epidemiology of Ebstein's anomaly in Europe and its association with maternal health and medication exposure during pregnancy. Design: We carried out a descriptive epidemiological analysis of population-based data. Setting: We included data from 15 European Surveillance of Congenital Anomalies Congenital Anomaly Registries in 12 European countries, with a population of 5.6 million births during 1982-2011. Participants: Cases included live births, fetal deaths from 20 weeks gestation, and terminations of pregnancy for fetal anomaly. Main outcome measures: We estimated total prevalence per 10,000 births. Odds ratios for exposure to maternal illnesses/medications in the first trimester of pregnancy were calculated by comparing Ebstein's anomaly cases with cardiac and non-cardiac malformed controls, excluding cases with genetic syndromes and adjusting for time period and country. Results: In total, 264 Ebstein's anomaly cases were recorded; $81 \%$ were live births, $2 \%$ of which were diagnosed after the 1 st year of life; $54 \%$ of cases with Ebstein's anomaly or a co-existing congenital anomaly were prenatally diagnosed. Total prevalence rose over time from 0.29 (95\% confidence interval (CI) $0.20-0.41$ ) to 0.48 (95\% CI $0.40-0.57$ ) $(\mathrm{p}<0.01)$. In all, nine cases were exposed to maternal mental health conditions/medications (adjusted odds ratio (adjOR) 2.64, 95\% CI 1.33-5.21) compared with cardiac controls. Cases were more likely to be exposed to maternal $\beta$-thalassemia (adjOR 10.5, 95\% CI 3.13-35.3, $\mathrm{n}=3$ ) and haemorrhage in early pregnancy (adjOR $1.77,95 \%$ CI $0.93-3.38, \mathrm{n}=11)$ compared with cardiac controls. Conclusions: The increasing prevalence of Ebstein's anomaly may be related to better and earlier diagnosis. Our data suggest that Ebstein's anomaly is associated with maternal mental health problems generally rather than lithium or benzodiazepines specifically;
\end{abstract}

Correspondence to: B. Boyle, Room 12L14, School of Nursing, Ulster University, Shore Road, Newtownabbey, Co. Antrim, BT37 0QB, United Kingdom. Tel: +44 2890 366 588; Fax: +442890368 341; E-mail: b.boyle1@ulster.ac.uk 
therefore, changing or stopping medications may not be preventative. We found new associations requiring confirmation.

Keywords: Ebstein's anomaly; prevalence; antidepressants; psycholeptics; mental illness

Received: 4 April 2016; Accepted: 29 May 2016; First published online: 30 August 2016

$\mathrm{E}$ BSTEIN'S ANOMALY IS A RARE, CONGENITAL CARDIAC anomaly of the tricuspid valve and the right ventricle first described by Wilhelm Ebstein in 1866. ${ }^{1}$ Cases were traditionally diagnosed at all ages, with the worst outcomes in neonates who need interventions for cyanotic disease. ${ }^{2}$ Diagnosis is increasingly happening prenatally; as this anomaly develops throughout fetal life, it can occur in cases with an apparently structurally normal heart on earlier ultrasonic scan. ${ }^{3}$ High rates of spontaneous abortion throughout pregnancy have been reported. ${ }^{4}$

An association between Ebstein's anomaly and maternal lithium exposure was first reported in the $1970 \mathrm{~s}^{5}$ and led to recommendations that are still in place today to switch to other antipsychotics during pregnancy where possible, ${ }^{6}$ but this association has been disputed in more recent literature. ${ }^{7}$ Associations have also been found with other exposures, including benzodiazepines, ${ }^{8}$ antihypertensives, ${ }^{9}$ valproic acid, ${ }^{10}$ marijuana, ${ }^{11}$ and organic solvents. ${ }^{11}$

A previous study of congenital anomalies associated with selective serotonin reuptake inhibitors use, using some of the same data, found an association with Ebstein's anomaly. ${ }^{12}$ The aims of the present study were to test the robustness of this finding by using a larger population and different controls and set it in the context of other mental health-related exposures, as well as to ascertain other aspects of the epidemiology of Ebstein's anomaly.

\section{Methods}

The European Surveillance of Congenital Anomalies (EUROCAT) is a network of population-based registries of congenital anomalies in 21 countries of Europe. ${ }^{13}$ The methods of registry case ascertainment are fully described elsewhere. ${ }^{14}$ The central database includes standardised data on live-born congenital anomaly cases, stillborn cases and fetal deaths after 20 weeks of gestation, and prenatally diagnosed cases resulting in termination of pregnancy for fetal anomaly; 1-week survival is also ascertained for liveborn cases. ${ }^{15}$ All registries record diagnoses made prenatally or at birth, most registries record diagnoses made up to 1 year of life, and some registries record diagnoses made in later childhood. ${ }^{14}$
The 15 EUROCAT congenital anomaly registries in 12 countries (Table 1), which agreed to take part, collect data on maternal illness before and during pregnancy and on maternal drug exposure in the first trimester of pregnancy. Most sources of exposure data were prospective to outcome, except in one centre where exposure data are ascertained exclusively by interviewing mothers and clinicians after the congenital anomaly has been diagnosed; three other registries use maternal interviews to confirm their data (Table 1).

Other variables used in this study were syndrome and malformation diagnoses, coded to International Classification of Diseases versions 9 and 10 with British Paediatric Association extension, family history of congenital anomaly, maternal age and parity, and gestational or postnatal age at diagnosis. ${ }^{15}$ Denominators including live births and stillbirths are available by registry and year.

The total study population was 5,644,312 births covering the years 1982-2011. (Table 1; Supplementary Table 1A). In total, 145,084 babies/fetuses with major congenital anomalies were registered, of which 264 were diagnosed as having Ebstein's anomaly (Table 1). All cases were included in the descriptive prevalence study. A case-malformed control study was also carried out comparing cases of Ebstein's anomaly with controls with cardiac and non-cardiac major malformations from the database separately. Excluded from both cases and controls were cases with chromosomal syndromes (11 cases and 20,316 controls), genetic syndromes (two cases and 2898 controls), skeletal dysplasia (no cases and 649 controls), and teratogenic syndromes (one case and 677 controls). Controls with only hip dysplasia $(n=5698)$, associated with higher gestational age at birth, were also excluded, leaving 250 cases and 35,904 controls with cardiac and 78,678 with noncardiac anomalies for the analysis of maternal and family exposures (see Supplementary Fig 1A for details of exclusions). Analyses of maternal medication involved 173 EA cases and 26,184 cardiac and 51,024 non-cardiac controls from a population of 3,662,154 births since 1995 (see Supplementary Fig 1A) as medication data were not available for all years (Table 1). International Classification of Diseases 9/10 codes for maternal diseases/conditions 
Table 1 . Study population (births) by country and year.

\begin{tabular}{|c|c|c|c|c|c|}
\hline \multirow{2}{*}{$\frac{\text { Countries }}{\text { Denmark (Odense) }{ }^{\mathrm{M}}}$} & \multirow{2}{*}{$\begin{array}{l}\text { Years included } \\
\text { in the study }\end{array}$} & \multirow{2}{*}{$\begin{array}{l}\text { Years included } \\
\text { in medication } \\
\text { analysis }\end{array}$} & \multirow{2}{*}{$\begin{array}{l}\text { Study population } \\
\text { 1982-2011: total } \\
\text { births }\end{array}$} & \multicolumn{2}{|c|}{$\begin{array}{l}\text { Ebstein's anomaly: number of } \\
\text { cases and prevalence per 100,000 } \\
\text { births (with 95\% CIs) 1982-2011 }\end{array}$} \\
\hline & & & & 10 & $0.63(0.34-1.16)$ \\
\hline France $\left(\right.$ Paris) ${ }^{\mathrm{M}}$ & $1982-1011$ & $2001-2011$ & 994,614 & 61 & $0.61(0.48-0.79)$ \\
\hline The Netherlands (Northern) ${ }^{\mathrm{M}, \mathrm{I}, \mathrm{P}}$ & $1982-2011$ & $1995-2001$ & 506,121 & 26 & $0.51(0.35-0.75)$ \\
\hline Switzerland (Vaud) ${ }^{\mathrm{M}}$ & 1989-2011 & $1997-2001$ & 174,162 & 13 & $0.75(0.43-1.29)$ \\
\hline Malta $^{\mathrm{M}}$ & $1986-2010$ & 1996-2011 & 115,713 & 11 & $0.95(0.53-1.72)$ \\
\hline Belgium (Antwerp) ${ }^{\mathrm{M}}$ & $1990-2011$ & $1997-2011$ & 341,573 & 12 & $0.35(0.20-0.62)$ \\
\hline Germany (Saxony) ${ }^{\mathrm{M}, \mathrm{I}}$ & $1987-2011$ & $2000-2011$ & 352,844 & 12 & $0.34(0.19-0.60)$ \\
\hline Ukraine $^{\mathrm{M}}$ & $2005-2011$ & $2005-2011$ & 208,772 & 13 & $0.62(0.36-1.07)$ \\
\hline Ireland ${ }^{*}, \mathrm{M}$ & $1996-2011$ & $1996-2011$ & 232,388 & 11 & $0.47(0.26-0.85)$ \\
\hline Italy**,M,I,X & $1982-2011$ & $1995-2011$ & $1,496,807$ & 40 & $0.27(0.20-0.36)$ \\
\hline United Kingdom (Wales) $^{\mathrm{M}}$ & $1998-2011$ & $1998-2011$ & 466,301 & 32 & $0.69(0.49-0.97)$ \\
\hline Spain $* * *, \mathrm{M}^{\circ}$ & $1990-2010$ & $1995-2011$ & 595,422 & 23 & $0.39(0.26-0.58)$ \\
\hline Total & 1982-2011 & 1995-2011 & $5,644,312$ & 264 & $0.47(0.41-0.53)$ \\
\hline
\end{tabular}

$\mathrm{CI}=$ confidence interval

* Ireland $=$ Cork and Kerry 1996-2010 and SE Ireland 1997-2010

** Italy = Tuscany 1982-2011 and Emilia Romagna 1982-2011

${ }^{* * * *}$ Spain $=$ Basque Country 1990-2010 and Valencia 2007-2010

${ }^{\mathrm{M}}$ Medication ascertainment from maternal medical/midwifery notes

${ }^{\mathrm{I}}$ Information on medication exposure taken from or confirmed through maternal interviews

${ }^{\mathrm{P}}$ Information available on maternal prescriptions

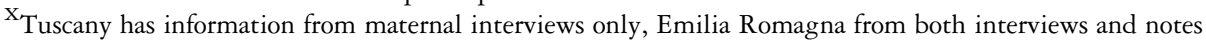

and Anatomical Therapeutic Chemical codes for medication corresponding to the categories analysed are given in the online Supplementary Table 2A. Maternal diabetes included both pre-gestational and gestational diabetes due to the potential for undiagnosed pre-gestational diabetes among those with gestational diabetes ${ }^{16,17}$ and the possibility of late development of Ebstein's anomaly. ${ }^{3}$

\section{Statistical analysis}

Total prevalence of Ebstein's anomaly cases per 10,000 births was calculated as follows:

Number of Ebstein's anomaly cases (live births + fetal deaths + terminations of pregnancy for fetal anomaly) $\times 10,000$

Total number of babies (live births + stillbirths) in the population

Prevalence and proportions by prenatal diagnosis and pregnancy outcome were calculated for three time periods (Fig 1) and for each country for the years 1992-2011 (Fig 1) when prevalence had stabilised in time.

Odds ratios, with $95 \%$ CIs, estimated using logistic regression to analyse risk factors are only presented where there are at least three exposed Ebstein's anomaly cases. Odd ratios were adjusted for year of birth, with the data divided into the time periods 1982-1991, 1992-2001, and 2002-2011 - and country (pooling data from registries within the same country: Table 1). For analysis of maternal age,
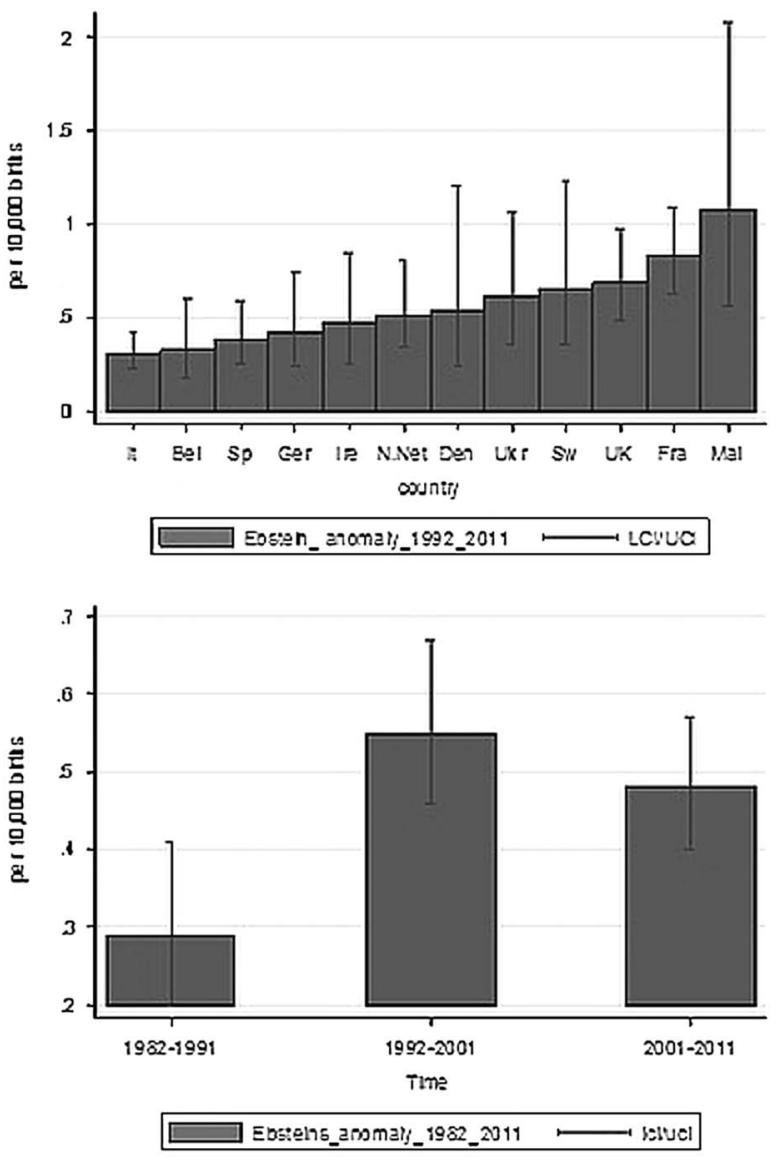

Figure 1.

Ebstein's anomaly: prevalence per 10,000 births over time and by country with $95 \%$ confidence intervals. 
maternal age was divided into three groups: $<25$, 25-34, and $>34$. All cases exposed to maternal diabetes, even if it occurred later in pregnancy, were excluded from the mental health analysis and vice versa to avoid confounding.

Previous hypotheses for investigation were lithium, selective serotonin reuptake inhibitors, other mental health medications, maternal depression and other mental health conditions, and maternal diabetes. For other exposures, an exploratory analysis first examined the data to find out which maternal diseases/ conditions and medication exposures were recorded for at least three Ebstein's anomaly cases, and these exposures were then subject to statistical analysis.

\section{Results}

Associated syndromes, malformations, and family bistory Of the 264 Ebstein's anomaly cases, $11(4.17 \%)$ had chromosomal anomalies (Supplementary Table 3A), less than the $11.9 \%$ proportion of chromosomal anomalies among non-Ebstein cardiac anomaly cases; two cases $(0.76 \%)$ were diagnosed with other genetic syndromes (Supplementary Table 3A) compared with $2.35 \%$ of other cardiac anomalies. A few cases had any recorded family history (Supplementary Table 4A). Of the 250 non-syndromic Ebstein's anomaly cases, 86 had other cardiac anomalies (34\%), including 23 reported as having an atrial septal defect only; twenty Ebstein's anomaly cases had other right ventricular outflow tract obstruction anomalies - pulmonary valve atresia or stenoses - and nine cases had coarctation of the aorta. Ebstein's anomaly cases were less likely to be associated with non-cardiac anomalies $(8.8 \%, 22$ cases) than other cardiac anomaly cases (17.6\%) (Supplementary Table 5A). No specific anomaly was associated with Ebstein's anomaly in more than two cases.

Prevalence, age at diagnosis, pregnancy outcome, and sex ratio

The average total prevalence of Ebstein's anomaly was 0.47 (95\% CI $0.41-0.53)$ per 10,000 births ranging from 0.27 (95\% CI $0.20-0.36)$ in Italy to 0.95 (95\% CI 0.53-1.72) in Malta (Table 1). The total prevalence rose significantly from 0.29 (95\% CI 0.20-0.41) in the decade 1982-1991 to 0.55 (95\% CI 0.46-0.67) in the decade 1992-2001 (trend $\mathrm{p}<0.01)$ remaining high at $0.48(95 \% \mathrm{CI}$ 0.40-0.57) in the decade 2002-2011 (Fig 1; Supplementary Table 6A). The decrease in prevalence between the second and third decades was not statistically significant.

The prevalence of prenatally diagnosed cases, where either Ebstein's anomaly or an associated
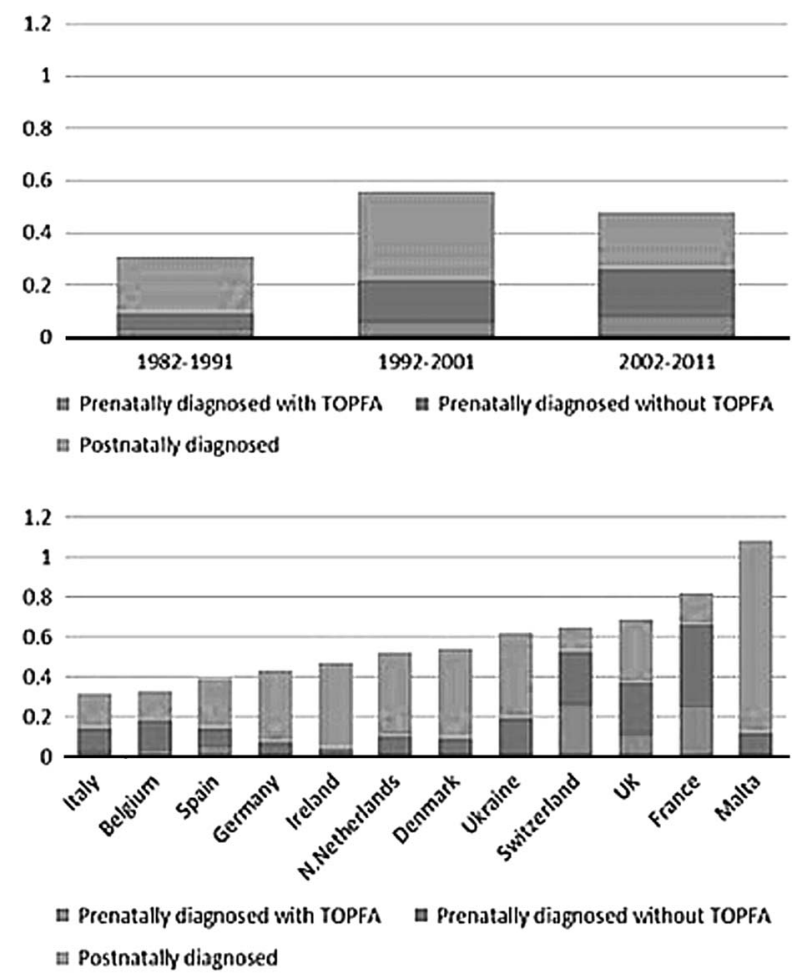

Figure 2.

Ebstein's anomaly: prevalence per 10,000 birtbs by time, country, termination of pregnancy for fetal anomaly (TOPFA) and prenatal diagnosis.

anomaly were prenatally diagnosed, per 10,000 births rose over time and varied between countries (Fig 2). The proportion of all cases that were prenatally diagnosed rose over time to $54 \%$ in the last decade (Fig 2) with 57\% of all the isolated Ebstein's anomaly cases prenatally diagnosed in that decade. The proportion of terminations of pregnancy for fetal anomaly rose to $16.7 \%$ in the last decade (Fig 3). The prevalence and proportion of terminations of pregnancy for fetal anomaly varied between countries (Fig 3). Termination of pregnancy for fetal anomaly is illegal in both Malta and Ireland. Of the 97 prenatally diagnosed, non-syndromic cases where gestational age at diagnosis was known, 85 (87.6\%) were diagnosed at or after 20 weeks of gestation and $44(45.4 \%)$ after 24 weeks of gestation. Overall, $16.5 \%$ of postnatally diagnosed live-born cases were diagnosed after the 1st week of life, not varying substantially between decades. Only five cases (2\%) were diagnosed after 1 year of life.

In all, 16 Ebstein's anomaly cases were stillbirths, 0.03 (95\% CI 0.02-0.05) per 10,000 births (Fig 3); 22 Ebstein's anomaly cases were known to be early neonatal deaths, a rate of 0.04 (95\% CI 0.03-0.06) per 10,000 births (Fig 3).

Out of 250 non-syndromic cases, $50.8 \%$ were male, excluding three cases of unknown sex. 


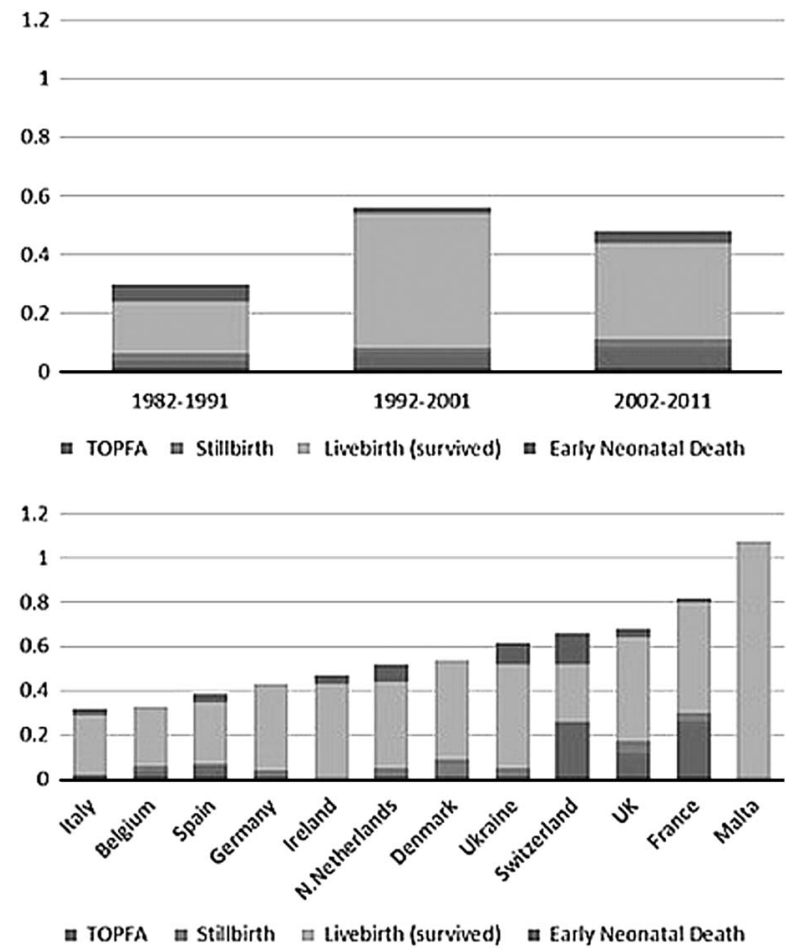

Figure 3.

Ebstein's anomaly: prevalence per 10,000 births by time, country, termination of pregnancy for fetal anomaly (TOPFA) and pregnancy outcome.

Case-malformed control analysis of risk factors. Neither the odds of older or younger maternal age was significantly different from controls (Table 2), but the odds of being a firstborn child, adjusted for maternal age, were significantly lower than that of all controls (Table 2). Cases were non-significantly more likely to have been from multiple births than non-cardiac controls (Table 2). There was one pair of co-twins concordant for Ebstein's anomaly, a monozygotic pair with twin-to-twin transfusion. Ebstein's anomaly cases were non-significantly less likely to have had assisted reproduction than either control group (Table 2).

In total, nine cases were exposed to mental illness and/or an antidepressant or a psycholeptic medication or both (adjOR 2.80, 95\% CI 1.42-5.51, noncardiac controls, Table 2). The odds ratio was similar when compared with cardiac controls (adjOR 2.64, 95\% CI 1.33-5.21), indicating that this effect was specific to Ebstein's anomaly (Table 2). High odds ratios were found for all the subcategories analysed psycholeptic medications, antidepressants, selective serotonin reuptake inhibitors, diagnosis of anxiety, diagnosis of depression (Table 2). No Ebstein's anomaly case was exposed to lithium, but five cardiac and eight non-cardiac controls were exposed to lithium. Further details of exposures of Ebstein's anomaly cases are given in the footnote of Table 2; three of the five cases of selective serotonin reuptake inhibitors exposure we found were also found in our previous study, ${ }^{12}$ which covered an overlapping population - that is, $28 \%$ of the population of this study.

Ebstein's anomaly was non-significantly associated with diabetes compared with non-cardiac controls and was as likely to be associated with diabetes as other cardiac anomalies (Table 2). Cases were not more likely than controls to have been exposed to non-psychotropic/non-diabetic medications (0.87, 95\% CI 0.54-1.39, Table 2).

Cases were more likely to have been exposed to maternal $\beta$-thalassemia (adjOR 12.9 (95\% CI 3.85-43.0)) based on only three cases (Table 2). Haemorrhage in early pregnancy/threatened abortion was associated with an elevated odds ratio (Table 2).

\section{Discussion}

\section{Ebstein's anomaly and mental health conditions and their medication}

We found that the risk of Ebstein's anomaly rises nearly threefold when the mother is reported to have mental health conditions with medication. Our data suggest that it is not lithium or benzodiazepines specifically that are associated with Ebstein's anomaly as had been previously assumed ${ }^{5,7,8}$ or Selective Serotonin Reuptake Inhibitors specifically as we and others had previously shown, ${ }^{2}$ but that medicated mental illness in general is a risk factor. We had no data on unmedicated mental illness, and cannot effectively distinguish medication from indication, although the lack of a specific medication effect points to the possibility of the risk being associated with the underlying health condition. Our analyses suggest that switching away from specific medications such as lithium does not protect the fetus. Our data also robustly suggest that these exposures are much more strongly associated with Ebstein's anomaly than cardiac anomalies in general. Recent literature has explored the relationships between congenital cardiac anomalies and both psychiatric conditions and the complex combinations of medications used to control them; other exposures of sufferers may also influence risk or act as confounders. ${ }^{18}$ We had no systematic data on factors such as smoking, alcohol, or recreational drugs. We excluded those with diabetes from the mental health analyses to avoid confounding due to the association of diabetes and depression. ${ }^{19}$

\section{Ebstein's anomaly and other maternal illnesses}

Pre-gestational diabetes is known to be associated with cardiac and other congenital anomalies, ${ }^{17,20}$ but has not been specifically investigated with regard to 
Table 2. Ebstein's anomaly: number, crude odds ratios (OR), and odds ratios adjusted for country and time (adjOR) for maternal characteristics and medication exposures compared with non-cardiac malformed control cases.

\begin{tabular}{|c|c|c|c|c|c|c|c|}
\hline \multirow[b]{2}{*}{ Exposures } & \multirow[b]{2}{*}{$\begin{array}{l}\text { Cases } \\
\text { exposed }\end{array}$} & \multicolumn{3}{|c|}{ Non-cardiac controls } & \multicolumn{3}{|c|}{ Cardiac controls } \\
\hline & & $\begin{array}{l}\text { Controls } \\
\text { exposed }\end{array}$ & OR $(95 \% \mathrm{CI})$ & $\begin{array}{l}\text { Adjusted for } \\
\text { country and time }\end{array}$ & $\begin{array}{l}\text { Controls } \\
\text { exposed }\end{array}$ & OR $(95 \% \mathrm{CI})$ & $\begin{array}{l}\text { Adjusted for } \\
\text { country and time }\end{array}$ \\
\hline \multicolumn{8}{|l|}{ Maternal reproductive history } \\
\hline Firstborn* & 69 & 24,660 & $0.72(0.54-0.96)$ & $0.70(0.52-0.95)$ & 11,255 & $0.76(0.57-1.02)$ & $0.74(0.56-0.99)$ \\
\hline Maternal age $<25$ & 52 & 15,165 & $1.10(0.80-1.51)$ & $1.14(0.82-1.58)$ & 6388 & $1.18(0.86-1.62)$ & $1.24(0.89-1.73)$ \\
\hline Maternal age $>34$ & 45 & 14,078 & $1.02(0.73-1.42)$ & $1.03(0.74-1.45)$ & 6932 & $0.94(0.67-1.32)$ & $0.95(0.68-1.33)$ \\
\hline $\mathrm{ART}^{* *}$ & 4 & 1862 & $0.65(0.24-1.75)$ & $0.61(0.23-1.66)$ & 885 & $0.65(0.24-1.74)$ & $0.58(0.22-1.58)$ \\
\hline Multiple birth & 14 & 3084 & $1.51(0.88-2.59)$ & $1.48(0.86-2.55)$ & 1746 & $1.18(0.69-2.03)$ & $1.17(0.68-2.02)$ \\
\hline \multicolumn{8}{|l|}{ Mental health $\mathrm{XD}$} \\
\hline Mental illness or medication $\mathrm{XD}, * * *$ & 9 & 962 & $3.04(1.56-5.94)$ & $2.80(1.42-5.51)$ & 497 & $2.65(1.35-5.18)$ & $2.64(1.33-5.21)$ \\
\hline Depression $\mathrm{XD}$ & 4 & 330 & $3.89(1.44-10.5)$ & $3.52(1.19-8.91)$ & 203 & $2.84(1.05-7.71)$ & $2.70(0.98-7.43)$ \\
\hline Anxiety ${ }^{X D}$ & 3 & 56 & $17.2(5.34-55.3)$ & $15.4(4.72-49.9)$ & 34 & $12.7(3.89-41.8)$ & $13.8(4.15-45.8)$ \\
\hline Psycholeptic (N05) ${ }^{\mathrm{m}, \mathrm{XD}}$ & 4 & 266 & $4.56(1.68-12.4)$ & $4.50(1.64-12.3)$ & 122 & $5.02(1.84-13.8)$ & $4.95(1.79-13.7)$ \\
\hline Antidepressants (N06A) $)^{\mathrm{m}, \mathrm{XD}}$ & 7 & 359 & $6.02(2.80-12.9)$ & $6.00(2.76-13.0)$ & 186 & $5.86(2.71-12.7)$ & $6.04(2.75-13.2)$ \\
\hline SSRIs (N06AB) ${ }^{\mathrm{m}, \mathrm{XD}}$ & 4 & 234 & $5.19(1.91-14.1)$ & $5.24(1.91-14.4)$ & 116 & $5.29(1.93-14.5)$ & $5.35(1.93-14.9)$ \\
\hline SSRI excluding other antidepressants ${ }^{\mathrm{m}, \mathrm{XD}}$ & 4 & 234 & $5.27(1.94-14.3)$ & $5.39(1.96-14.8)$ & 116 & $5.37(1.96-14.7)$ & $5.49(1.97-15.3)$ \\
\hline Antidepressants excluding Psycholeptics ${ }^{\mathrm{m}, \mathrm{XD}}$ & 5 & 303 & $5.13(2.09-12.6)$ & $5.32(2.14-13.2)$ & 159 & $4.97(2.01-12.3)$ & $5.22(2.08-13.1)$ \\
\hline Mental illness excluding psycholeptics ${ }^{\mathrm{m}, \mathrm{XD}}$ & 5 & 601 & $2.57(1.05-6.29)$ & $2.50(1.01-6.16)$ & 341 & $2.29(0.93-5.61)$ & $2.14(0.87-5.29)$ \\
\hline Non-mental health/non-diabetic medications ${ }^{\mathrm{m}}$ & 23 & 7923 & $0.88(0.57-1.37)$ & $0.87(0.54-1.40)$ & 3937 & $0.90(0.58-1.40)$ & $0.89(0.56-1.43)$ \\
\hline \multicolumn{8}{|l|}{ Disease/condition } \\
\hline Diabetes XP & 6 & 1285 & $1.52(0.67-3.42)$ & $1.51(0.67-3.40)$ & 1063 & $0.82(0.37-1.86)$ & $0.87(0.38-1.96)$ \\
\hline$\beta$-thalassemia ${ }^{\mathrm{XP}, \mathrm{XD}}$ & 3 & 114 & $8.65(2.73-27.4)$ & $12.9(3.85-43.0)$ & 65 & $6.81(2.13-21.8)$ & $10.5(3.13-35.3)$ \\
\hline Haemorrhage in early pregnancy $\mathrm{XP}, \mathrm{XD}$ & 11 & 1602 & $2.29(1.25-4.21)$ & $1.77(0.92-3.38)$ & 771 & $2.14(1.16-3.93)$ & $1.77(0.93-3.38)$ \\
\hline \multicolumn{8}{|l|}{ Maternal infection } \\
\hline Genitourinary infection $\mathrm{XP}, \mathrm{XD}$ & 3 & 799 & $1.22(0.39-3.83)$ & $1.02(0.32-3.24)$ & 394 & $1.11(0.36-3.49)$ & $1.03(0.33-3.28)$ \\
\hline Antibiotics $(\mathrm{J} 01)^{\mathrm{m}, \mathrm{XP}, \mathrm{XD}}$ & 6 & 1277 & $1.47(0.65-3.33)$ & $1.68(0.73-3.87)$ & 632 & $1.50(0.66-3.40)$ & $1.80(0.78-4.15)$ \\
\hline
\end{tabular}

$\mathrm{CI}=$ confidence interval

Bold values are statistically significant

${ }^{\mathrm{m}}$ Analysis restricted to years with medication data available (Table 1)

${ }^{\mathrm{XP}}$ Excluding cases and controls exposed to mental health issues (zero cases, 18 cardiac, 40 non-cardiac controls). Two pre-gestational, three gestational

${ }^{\mathrm{XD}}$ Excluding cases and controls exposed to diabetes (zero cases, 18 cardiac, 40 non-cardiac controls)

${ }^{*}$ Cases and controls where the total number of previous pregnancies was unknown were excluded (47 (18.8\%) cases 16,958 (21.6\%) controls). OR

adjusted for country and time were also adjusted for maternal age

***1992-2011 only

${ }^{* * *}$ There were no cases with recorded exposure to maternal mental illness who were not exposed to psycholeptic or antidepressant medications; three of the nine cases with medications had no diagnosis recorded, including one who took an antipsychotic. In addition, two cases exposed to psycholeptics, both exposed to a benzodiazepine derivative (anxiolytics), were also exposed to a Selective Serotonin Reuptake Inhibitor (SSRI). There were two cases exposed to SSRIs only; one mother, who took both a benzodiazepine derivatives and an SSRI, was also using $\beta$-blockers and drinking $>5$ units of alcohol per day. The other eight had no relevant medical history, were not known to have used assisted reproductive therapies (ART), and all had singleton births

Ebstein's anomaly. Ebstein's anomaly, although it can be detected as early as 14 weeks of gestation, is known to occasionally develop later in pregnancy. ${ }^{3}$ It has been hypothesised that as women diagnosed with gestational diabetes are more likely to be overweight or obese they may have suffered from undiagnosed type 2 diabetes before pregnancy, ${ }^{17}$ and thus we grouped gestational and pre-gestational disease together, finding a weak association between Ebstein's anomaly and diabetes when compared with non-cardiac controls. This odds ratio is likely to be underestimated because of the inclusion in the control group of other malformations associated with diabetes. ${ }^{17,20}$ The lack of elevated odds compared with cardiac controls suggests that Ebstein's anomaly has a similar association with diabetes as cardiac anomalies in general. ${ }^{17,20}$ Although an association was found between right ventricular outflow tract anomalies and pre-gestational diabetes in one study, none of the exposed cases in that study had Ebstein's anomaly, ${ }^{17}$ and five exposed cases were not available for analysis in another; ${ }^{20}$ therefore, we conclude that, although diabetes is an important risk factor for congenital cardiac anomalies in general, it is not specifically associated with Ebstein's anomaly.

We were not able to confirm an association between maternal febrile illness, especially genitourinary tract infections, and right ventricular outflow tract obstructions ${ }^{21}$ as being specific to Ebstein's anomaly.

Our finding that there is a strong association with $\beta$-thalassemia is new, but it is based on only three cases and not hypothesis driven, and thus needs confirmation in an independent data set.

\section{Epidemiology of Ebstein's anomaly}

We estimate a prevalence of Ebstein's anomaly in Europe of 0.47 cases per 10,000 births, which is consistent with those in other populations -0.39 per 10,000 births in Hawaii (1986-1999), ${ }^{22} 0.52$ 
per 10,000 births in Baltimore (1981-1989), ${ }^{8} 0.6$ per 10,000 in Atlanta (1992-2005), ${ }^{23}$ and 0.72 per 10,000 births in Texas (1999-2005). ${ }^{24}$ Our cases were drawn from a population of 5.6 million births, more than twice the population of the next largest of these studies. ${ }^{24}$ The highest European prevalence in our study was found in Malta where the estimate is based on small numbers, but where the prevalence of congenital cardiac anomalies is known to be high relative to the rest of Europe. ${ }^{25,26}$

The significant increase in prevalence that we found from the 1980s to the 1990s may be due in part to the increase in prenatal diagnosis and in terminations of pregnancy for fetal anomaly as a proportion of cases was lost spontaneously in late pregnancy. ${ }^{3,4}$ Prenatal and early diagnosis may also lead to better ascertainment of cases that might have been diagnosed later in life in the first study decade or missed in late fetal and neonatal deaths. More than half of cases were prenatally diagnosed since the 1990s, mostly after 20 weeks of gestation, and often diagnosed after 24 weeks of gestation. There is evidence that the majority of cases can be diagnosed by ultrasound as early as 14 weeks of gestation, ${ }^{3}$ and, although infrequently Ebstein may develop after 20 weeks, diagnosis in late pregnancy may reflect the timing of routine congenital anomaly scans throughout Europe. ${ }^{27}$

Our finding that Ebstein's anomaly is less likely to be part of chromosomal syndromes than other cardiac anomalies is consistent with other studies. ${ }^{8}$ Less than $1 \%$ of our cases were known to have a monogenic or microdeletion syndrome, but this may be partly because specific genetic testing has been infrequently carried out; two cases - both terminations of pregnancy for fetal anomaly - were reported to have thymic agenesis, which could indicate an undiagnosed genetic syndrome. In genetic studies of the disease, microdeletions have been found. ${ }^{28}$ Although there are reports of familial associations of the disease, these are rare, ${ }^{29}$ and first-degree relatives of Ebstein's anomaly cases are more likely to have other CHDs. ${ }^{30}$

The association of Ebstein's anomaly with multiple births is inconsistent in the literature ${ }^{23,24}$ and we found only a weak association. It is interesting that, similar to Correa-Villasenor and co-workers, ${ }^{8}$ we found a twin pair concordant for Ebstein's anomaly. Monozygotic twins are usually discordant for CHD, with the lesion possibly occurring either as a result of a disturbance in laterality in one twin during separation or as a result of imbalance in placental blood flow. ${ }^{31}$ Although our twins did have a twin-totwin transfusion, it is difficult to imagine that such a transfusion caused an identical lesion in both the donor and the recipient twin - more likely there was a genetic disposition, a teratogenic cause, or a combination of both. Correa-Villasenor's twins were reportedly dizygotic and had an older sibling also diagnosed with Ebstein's anomaly; one of the other twins in our data was reported to have had a twin-totwin transfusion, but in that case the co-twin was not reported as having a congenital anomaly. We can hypothesise that the higher rate of haemorrhage in early pregnancy/threatened abortion in cases than controls, although not reaching statistical significance, may indicate the early loss of co-twins. ${ }^{32}$

Our finding that Ebstein's anomaly cases are less likely to be firstborn children support the findings of Correa-Villasenor and co-workers, ${ }^{8}$ but our data do not support their findings of an association with older maternal age or assisted reproductive therapy.

\section{Strengths and limitations of this study}

The strengths of our study are the large population with standardised data on congenital anomaly diagnoses, the inclusion of all pregnancy outcomes such as live births, stillbirths, and terminations of pregnancy, and the prospective nature of most medication recording, blind to anomaly status. The main limitation of our data was probable under ascertainment of exposure status across a range of variables, although this would have been unbiased in the case-malformed control design. We used controls who had the same probability of exposure and of ascertainment of that exposure as the cases, ${ }^{3,34}$ and could therefore judge the specificity of association with Ebstein's anomaly in comparison both with non-cardiac and with other cardiac anomalies; however, the disadvantage of the case-malformed control design is that any exposure that is related to the controls will lead to an underestimate of the odds ratio for Ebstein's anomaly - the so called "teratogen non-specificity bias" 35 - for example, this could have diluted the OR for diabetes or selective serotonin reuptake inhibitors use where other anomalies are also implicated. ${ }^{12,17,20}$ We analysed multiple exposures in our exploratory analyses, and the results should be interpreted taking into account the possibility of chance associations. As Ebstein's anomaly may sometimes develop later than first trimester, ${ }^{3}$ later medication exposures may be aetiologically significant, but EUROCAT data include only first trimester exposures.

\section{Conclusions}

Ebstein's anomaly is diagnosed in approximately one in 21,000 babies in Europe. Ebstein's anomaly is associated with a range of maternal health conditions and related medications, and our data support and broaden previous literature. There is a new signal in our data for an association between Ebstein's anomaly 
and maternal $\beta$-thalassemia, which requires further confirmation.

\section{Acknowledgements}

The authors thank Hermien de Walle from University Medical Center Groningen, Department of Genetics, University of Groningen and the people throughout Europe involved in providing and processing information, including affected families, clinicians, healthcare professionals, medical record clerks, and registry staff.

\section{Financial Support}

This study was funded by European Operating Grant 20133307 UU. EUROCAT registries are funded as fully described in Paper 6 of Report 9 - EUROCAT Member Registries: Organization and Activities (http:// onlinelibrary.wiley.com/doi/10.1002/bdra.20775/pdf).

\section{Conflicts of Interest}

None.

\section{Ethical Standards}

Permission to carry out this study as part of the EUROCAT project was granted by the Institute of Nursing and Health Research, School of Nursing Research Governance Filter Committee at Ulster University on behalf of the Ulster University Ethics Committee.

\section{Supplementary materials}

To view supplementary material for this article, please visit http://dx.doi.org/10.1017/S1047951116001025

\section{References}

1. van Son JA, Konstantinov IE, et al. Wilhelm Ebstein and Ebstein's malformation. Eur J Cardiothorac Surg 2001; 20: 1082-1085.

2. Oxenius A, Attenhofer Jost CH, Pretre R, et al. Management and outcome of Ebstein's anomaly in children. Cardiol Young 2013; 23: $27-34$.

3. Zimmer EZ, Blazer S, Lorber A, et al. Fetal Ebstein's anomaly: early and late appearance. Prenat Diagn 2012; 32: 228-233.

4. Celermajer DS, Bull C, Till JA, et al. Ebstein's anomaly: presentation and outcome from fetus to adult. J Am Coll Cardiol 1994; 23: $170-176$.

5. Nora JJ, Nora AH, Toews WH. Letter: lithium, Ebstein's anomaly, and other congenital heart defects. Lancet 1974; 2: 594-595.

6. NICE. Antenatal and postnatal mental health: clinical management and service guidance - updated version. 2014; Retrieved February 11, 2015 from http://www.nice.org.uk/guidance/cg192/evidence/ cg192-antenatal-and-postnatal-mental-health-full-guideline3.

7. Diav-Citrin O, Shechtman S, Tahover E, et al. Pregnancy outcome following in utero exposure to lithium: a prospective, comparative, observational study. Am J Psychiatry 2014; 171: 785-794.
8. Correa-Villasenor A, Ferencz C, Neill CA, et al. Ebstein's malformation of the tricuspid valve: genetic and environmental factors. The Baltimore-Washington infant study group. Teratology 1994; 50: 137-147.

9. Caton AR, Bell EM, Druschel CM, et al. Antihypertensive medication use during pregnancy and the risk of cardiovascular malformations. Hypertension 2009; 54: 63-70.

10. Ozkan H, Cetinkaya M, Koksal N, et al. Severe fetal valproate syndrome: combination of complex cardiac defect, multicystic dysplastic kidney, and trigonocephaly. J Matern Fetal Neonatal Med 2011; 24: 521-524.

11. Jenkins KJ, Correa A, Feinstein JA, et al. Noninherited risk factors and congenital cardiovascular defects: current knowledge: a scientific statement from the American Heart Association Council on cardiovascular disease in the young: endorsed by the American Academy of Pediatrics. Circulation 2007; 115: 2995-3014.

12. Wemakor A, Casson K, Garne E, et al. Selective serotonin reuptake inhibitor antidepressant use in first trimester pregnancy and risk of specific congenital anomalies: a European register-based study. Eur J Epidemiol 2015; 11: 1187-1198.

13. Boyd PA, Haeusler M, Barisic I, et al. Paper 1: the EUROCAT network - organization and processes. Birth Defects Research 2011; 91 (Suppl 1): S2-15.

14. Greenlees R, Neville A, Addor MC, et al. Paper 6: EUROCAT member registries: organization and activities. Birth Defects Res $A$ Clin Mol Teratol 2011; 91 (Suppl 1): S51-S100.

15. EUROCAT. EUROCAT: Guide 1.3 and Reference Documents. 2013. Retrieved April 7, 2014 from http://www.eurocat-network. eu/content/EUROCAT-Guide-1.3.pdf.

16. Cowie CC, Rust KF, Ford ES, et al. Full accounting of diabetes and pre-diabetes in the U.S. population in 1988-1994 and 2005-2006. Diabetes Care 2009; 32: 287-294.

17. Correa A, Gilboa SM, Besser LM, et al. Diabetes mellitus and birth defects. Am J Obstet Gynecol 2008; 199: 237. e1-237.e9.

18. Monk C, Newport DJ, Korotkin JH, et al. Uterine blood flow in a psychiatric population: impact of maternal depression, anxiety, and psychotropic medication. Biol Psychiatry 2012; 72: 483-490.

19. Hasan SS, Clavarino AM, Dingle K, et al. Psychological health and the risk of diabetes mellitus in Australian women: a 21-year prospective study. J Womens Health (Larchmt) 2014; 23: 912-919.

20. Garne E, Loane M, Dolk H, et al. Spectrum of congenital anomalies in pregnancies with pregestational diabetes. Birth Defects Res A Clin Mol Teratol 2012; 94: 134-140.

21. Botto LD, Panichello JD, Browne ML, et al. Congenital heart defects after maternal fever. Am J Obstet Gynecol 2014; 210: 359. e1-359.e11.

22. Forrester MB, Merz RD. Descriptive epidemiology of selected congenital heart defects, Hawaii, 1986-1999. Paediatr Perinat Epidemiol 2004; 18: 415-424.

23. Reller MD, Strickland MJ, Riehle-Colarusso T, et al. Prevalence of congenital heart defects in metropolitan Atlanta, 1998-2005. J Pediatr 2008; 153: 807-813.

24. Lupo PJ, Langlois PH, Mitchell LE. Epidemiology of Ebstein anomaly: prevalence and patterns in Texas, 1999-2005. Am J Med Genet A. 2011; 155A: 1007-1014.

25. Dolk H, Loane M, Garne E, European Surveillance of Congenital Anomalies (EUROCAT) Working Group. congenital heart defects in Europe: prevalence and perinatal mortality, 2000 to 2005. Circulation 2011; 123: 841-849.

26. Khoshnood B, Loane M, Garne E, et al. Recent decrease in the prevalence of congenital heart defects in Europe. J Pediatr 2013; 162: 108-13.e2. 
Vol. 27, No. 4

27. Special Report: Prenatal Screening Policies in Europe 2010, Retrieved February 2, 2016 from http://www.eurocat-network.eu/ aboutus/publications/publications.

28. Postma AV, van Engelen K, van de Meerakker J, et al. Mutations in the sarcomere gene MYH7 in Ebstein anomaly. Circ Cardiovasc Genet 2011; 4: 43-50.

29. McIntosh N, Chitayat D, Bardanis M, et al. Ebstein anomaly: report of a familial occurrence and prenatal diagnosis. Am J Med Genet 1992; 42: 307-309.

30. Attenhofer Jost CH, Connolly HM, Dearani JA, et al. Ebstein's anomaly. Circulation 2007; 115: 277-285.

31. Manning $\mathrm{N}$. The influence of twinning on cardiac development. Early Hum Dev 2008; 84: 173-179.
32. Verp MS. Pregnancy loss: multiple pregnancy versus multiple birth. In: Blickstein I, Keith L, eds Multiple Pregnancy Epidemiology, Gestation and Perinatal Outcome, 2nd edn. Taylor and Francis, New York, 2005: 252-255.

33. Schlesselman J. Case-Control Studies. Oxford University Press, Oxford, 1982.

34. Dolk H, Wemakor A. Case-control studies require appropriate population controls: an example of error in the SSRI birth defect literature. Eur J Epidemiol 2015; 30: 1219-1221.

35. Prieto L, Martinez-Frias ML. Case-control studies using only malformed infants: are we interpreting the results correctly? Teratology 1999; 60: 1-2. 